\title{
FAKTOR LINGKUNGAN YANG MEMPENGARUHI PRODUKTIVITAS MENGGUNAKAN APLIKASI ANALISIS JALUR DI TAMBAK BANDENG KABUPATEN INDRAMAYU, PROVINSI JAWA BARAT
}

\author{
ENVIRONMENTAL FACTORS AFFECTING PRODUCTIVITY USING PATH ANALYSIS \\ APPLICATIONS IN PONDS MILKFISH INDRAMAYU DISTRICT, WEST JAVA PROVINCE
}

\author{
Admi Athirah, Ruzkiah Asaf dan Erna Ratnawati \\ Balai Penelitian dan Pengembangan Budidaya Air Payau \\ Jalan Makmur Daeng Sitakka 129 Maros 90512, Sulawesi Selatan \\ Email: m.athirah@gmail.com dan qiaasaf@gmail.com
}

Diterima tanggal: 7 Januari 2013, diterima setelah perbaikan: 15 April 2013, disetujui tanggal: 22 April 2013

\begin{abstract}
ABSTRAK
Faktor lingkungan berupa kualitas tanah dan air tambak adalah faktor yang sangat menentukan produktivitas tambak di Kabupaten Indramayu, Provinsi Jawa Barat.Namun demikian, belum ada informasi mengenai pengaruh faktor lingkungan terhadap produksi tambak bandeng di tambak Kabupaten Indramayu. Oleh karena itu dilakukan penelitian yang bertujuan untuk mengetahui pengaruh langsung atau tidak langsung kualitas tanah dan air terhadap produksi total di tambak Kabupaten Indramayu. Penelitian dilaksanakan di kawasan tambak Kecamatan Pasekan, Lohbener, Arahan, Cantigi, Losarang, Kandanghaur, Indramayu, Balongan dan Krangkeng. Data kualitas tanah dan air tambak dianalisis menggunakan aplikasi analisis jalur denganmenerapkan model mediasi, model rekursif dan model persamaan dua jalur di mana peubah kualitas tanah sebagai peubah bebas dan peubah kualitas air dan produksi tambak bandeng sebagai peubah tidak bebas. Hasil penelitian menunjukkan bahwa hasil analisis jalur kualitas tanah ada 2 peubah yang mempengaruhi produksi monokultur ikan bandeng yaitu: redoks (Eh) tanah dan pHF, sedangkan peubah kualitas air ada 3 peubah yang mempengaruhi produksi tambak ikan bandeng di Kabupaten Indramayu yaitu TSS (Padatan Tersuspensi) air, Bahan Organik Total (BOT) dan kandungan besi air. Redoks tanah mempunyai nilai pengaruh langsung sebesar 0,451 sedangkan pHF tanah senilai -0,305 terhadap produksi ikan bandeng di tambak. TSS air memiliki nilai pengaruh langsung sebesar 0,346, BOT air dengan nilai pengaruh langsung -0,291 dan kandungan besi (Fe) air sebesar -0,416 yang menunjukkan bahwa dari kelima peubah tanah dan air yang mempunyai nilai pengaruh langsung tersebut, nilai pHF $<0,3$ sedangkan peubah lainnya yaitu Eh tanah, TSS air, BOT air dan Fe air < 0,2.
\end{abstract}

Kata kunci: analisis jalur, bandeng, lingkungan, tambak, Indramayu

\section{ABSTRACT}

Environmental factors such as soil and water quality of ponds determine ponds productivity Indramayu district, West Java Province. However, there is no information on the effects of environmental factors on the production of milkfish in milkfish ponds in Indramayu regency. This research was aimed to determine the direct or indirect effects of pond soil and water quality on total pond production of Indramayu district. The experiment was conducted in Pasekan, Lohbener, Arahan, Cantigi, Losarang, Kandanghaur, Indramayu, Balongan and Krangkeng districts. Data were analysed using path analysis deploying mediation, recursive and two-equation models in which soil quality variables were threated as independent variables; whereas water quality variables and milkfish production were threated as dependent variables. The results of path analysis showed that two variables affected on soil quality were redox potential (Eh) and pHF and three variables affected on water quality were TSS, TOM and iron. The value of direct affected of soil redox potential was -0.45, while pHF was -0.305 against the production of milkfish in ponds. The value of direct effect of TSS, TOM and Fe were 0.346, -0.291 and -0.416 respectively. Of these five variables, the value of pHF was below than 0.3 while other variables: the values of redox potential, TSS, TOM and Fe were below to 0.2.

Keywords: environmental, Indramayu,milk fish,path analysis,pond

Faktor Lingkungan yang Mempengaruhi Produktivitas Menggunakan Aplikasi Analisis Jalur di Tambak Bandeng Kabupaten Indramayu, Provinsi Jawa Barat 


\section{PENDAHULUAN}

Kabupaten Indramayu yang secara geografis terletak di bagian selatan khatulistiwa merupakan salah satu Kabupaten di Propinsi Jawa Barat.Kondisi ekologis dan geografis dari Kabupaten Indramayu yang berada di pesisir atau berbatasan dengan laut Jawa sangat mendukung untuk pengembangan usaha kelautan dan perikanan, hal tersebut dibuktikan dengan total tambak yang dimiliki oleh Kabupaten Indramayu seluas 22.514,07 ha dengan komoditas unggulan meliputi udang, bandeng, dan rumput laut, menghasilkan jumlah produksi tambak pada tahun 2011 sebanyak 101.454 ton, dimana produksi ini meningkat cukup signifikan bila dibandingkan dengan tahun 2010 dan 2009 yang hanya berproduksi sebanyak 82.149 dan 42.658 ton (Anonim, 2011).

Secara umum, faktor lingkungan tambak (kualitas tanah dan air) adalah faktor penentu dominan dalam budidaya tambak sehingga dipertimbangkan sebagai kriteria dalam kesesuaian lahan untuk budidaya tambak (Boyd, 1995; Treece, 2000; Salam et al., 2003; Karthik et al., 2005; Mustafa et al., 2007).Beberapa hasil penelitian menunjukkan bahwa pemupukan, pengapuran, ketersediaan air dan adanya saluran merupakan pengaruh yang nyata yang berpengaruh terhadap produktivitas tambak di Kabupaten Maros, Takalar dan Bulukumba, Provinsi Sulawesi Selatan (Mustafa et al., 2007), dari hal tersebut diperlukan informasi yang lebih rinci mengenai hubungan sebab akibat dari kualitas tanah dan atau kualitas air kualitas tanah dan atau kualitas air dalammempengaruhi produksi. Faktor lingkungan tambak adalah faktor penting yang mempengaruhi produksi di tambak (Mustafa dan Ratnawati, 2005; Mustafa dan Sammut, 2007),sehingga informasi mengenai hubungan kualitas tanah dengan kualitas air yang mempengaruhi produksi tambak di Kabupaten Indramayu.

Analisis jalur (path analysis) adalah suatu teknik untuk menganalisis hubungan sebab akibat yang terjadi pada regresi berganda apabila peubah bebasnya mempengaruhi peubah tergantung, tidak hanya secara langsung, tetapi juga secara tidak langsung(Rutherford dan Choe, 1993; Everitt dan Dunn, 2001). Dalam perkembangannya, analisis jalur diperluas dan diperdalam ke dalam bentuk analisis Model Persamaan Struktural (Structural Equation Modeling $=$ SEM) (Sarwono, 2007).Karakteristik dasar penggunaan SEM harus melibatkan dua jenis variable, yaitu variable observasi dan laten. Variabel observasi mempunyai data seperti data angka atau skala penilaian yang diambil dari kuesioner.Disamping data tersebut didepan, Variabel observasi dalam SEM mencakup pula data kontinus. Sedang variable laten adalah variabel yang secara tidak langsung teramati namun ingin diketahui. Untuk melakukan observasi variable laten, harus membuat modelmodel yang mengekspresikan variable-variabel laten sebagai variabel observasi. Oleh karena itu pada penelitian ini digunakan SEM. Sesuai dengan hakikatnya, analisis jalur bukan difungsikan untuk mencari faktor penyebab, tetapi hanya membuat model kausal yang dapat digunakan untuk membuat penjelasan teoritis(Amir, 2006).Sehingga penelitian ini bertujuan untuk mengkarakteristik lingkungan tambak dan menganalisis hubungan kausal antarpeubah kualitas tanah dan kualitas air dan produksi tambak dengan tujuan untuk mengetahui pengaruh langsung atau tidak langsung kualitas tanah dan air terhadap produksi tambak di Kabupaten Indramayu menggunakan aplikasi analisis jalur. Dalam bidang perikanan SEM digunakan untuk memperkirakan perilaku secara akurat dengan menggunakan perspektif theory plannedbehavior dari nelayan artisanal di Indonesia di tengah kehidupan dengan kondisi degradasi sumberdaya laut yangsemakin menurun adanya, kemiskinan absolut yang dihadapi oleh nelayan artisanal, semakin kompleksnya persoalanpemanfaatan sumberdaya pesisir di Indonesia serta semakin beragamnya stakeholder pemanfaat sumberdaya tersebut(Prihandoko et al., 2011)

\section{BAHAN DAN METODE}

\section{Waktu dan Lokasi Penelitian}

Penelitian berupa pengambilan contoh tanah dan air serta wawancara dilaksanakan pada bulan September 2012 di Kecamatan Pasekan, Lohbener, Arahan, Cantigi, Losarang, Kandanghaur, Indramayu, Balongan dan Krangkeng. Analisis kualitas tanah dan air masing-masing dilaksanakan di Laboratorium Tanah dan Laboratorium Air, Balai Penelitian dan Pengembangan Budidaya Air Payau, Maros, Provinsi Sulawesi Selatan. 
Produksi tambak merupakan produksi bandeng (Chanos chanos).

\section{Pengumpulan Data}

Metode yang diterapkan dalam penelitian adalah metode survei. Data yang dikumpulkan meliputi kualitas tanah dan kualitas air serta produksibandeng. Sampel yang diperoleh sebanyak 148 sampel tanah dan 83 sampel air dari sembilan kecamatan dengan 34 titik pengambilan sampel.Pengukuran dan pengambilan contoh tanah dilakukan pada kedalaman 0-0,25 m. Kualitas tanah yang diukur secara in situ adalah $\mathrm{pH}_{\mathrm{F}}(\mathrm{pH}$ yang diukur langsung di lapangan) dengan menggunakan $\mathrm{pH}$ meter, $\mathrm{pH}_{\mathrm{FOX}}(\mathrm{pH}$ tanah yang diukur di lapangan setelah dioksidasi dengan hydrogen peroksida 30\%) dengan menggunakan $\mathrm{pH}$ meter dan potensial redoks diukur dengan redox-meter(Ahern et al., 2004). Contoh tanah yang diambil di lapangan dimasukkan dalam kantong plastik kemudian dimasukkan dalam cool box yang berisi es sesuai dengan metode Kjedhal,
$\mathrm{PO}_{4}$ dan $\mathrm{P}_{2} \mathrm{O}_{5}$ dengan metode Bray 1 (Eviati dan Sulaeman, 2009), $\mathrm{Fe}$ dan Al dengan spektrofotometer, Al dengan spektrofotometer menurut (Menon, 1973) dan tekstur meliputi pasir, liat dan debu dengan metode hidrometer (Agus et al., 2006). Pengukuran dan pengambilan contoh air di tambak mengikuti titik pengambilan contoh tanah. Peubah kualitas air yang diukur langsung di lapangan adalah suhu, salinitas, oksigen terlarut dan $\mathrm{pH}$ dengan menggunakan Hydrolab $^{\circledR}$ Minisonde. Contoh air untuk analisis di laboratorium diambil dengan menggunakan Kmerer Water Sampler dan dipreservasi mengikuti petunjuk APHA (2005).Peubah kualitas air yang dianalisis di laboratorium yaitu $\mathrm{NH}_{3}, \mathrm{NO}_{3}, \mathrm{NO}_{2}, \mathrm{PO}_{4}$, $\mathrm{Fe}, \mathrm{SiO}_{2}, \mathrm{SO}_{4}$ dan bahan organik totalmengikuti petunjuk Menon.Menon (1973), Aguset a(2006) danAPHA (2005). Peta yang menunjukkan titiktitik sampling penelitian tersaji pada gambar 1 berikut.

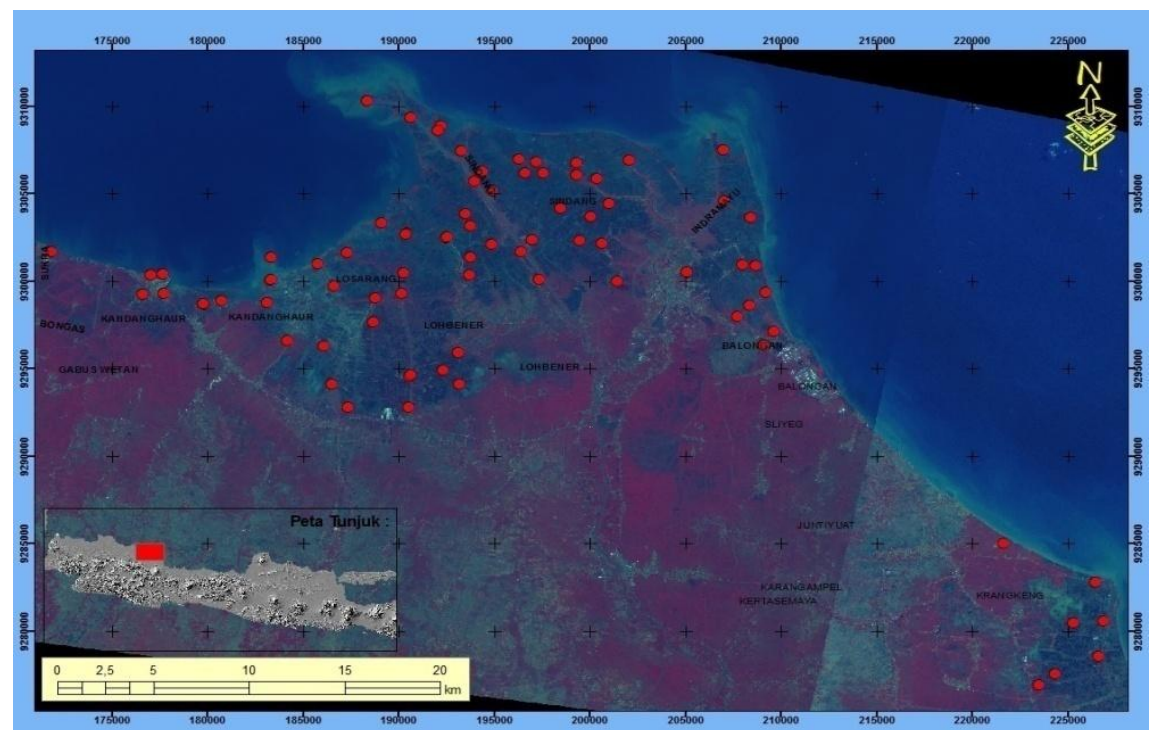

Gambar 1. Lokasi penelitian titik sampling di tambak Kabupaten Indramayu, Provinsi Jawa Barat (Locationof sampling pointsinthe studypondsIndramayuregency, West Java Province)

Seluruh titik-titik pengukuran dan pengambilan contoh ditentukan titik koordinatnya dengan menggunakan Global Positioning System (GPS).

Data produksi tambak diperoleh melalui wawancara dengan mengajukan kuesioner secara terstruktur terhadap responden. Responden terpilih adalah pengelola dari tambak yang diukur dan diambil contoh tanah dan contoh airnya., contoh tanah dan air diambil berdasarkan luas wilayah per kecamatan dan titik-titik yang dipandang perlu sebagai perwakilan daerah yang memungkinkan adanya pengaruh lingkungan dimana tambak tersebut berada, dari sembilan kecamatan, titik pengambilan sampel sebanyak 34 titik pengamatan yang dianggap penting. 


\section{Analisis Data}

Statistik deskriptif dan koefisien korelasi ditentukan untuk mendeteksi adanya gejala multikolinearitas yaitu gejala korelasi antar peubah kualitas tanah maupun kualitas air tambak. Untuk menghitung persamaan regresinya digunakan metode langkah mundur (backward) (Draper dan Smith, 1981). Uji R2, Uji F dan Uji t digunakan untuk mengetahui besarnya pengaruh peubah eksogenous terhadap peubah perantara secara parsial. Taraf signifikansi ditetapkan sebesar 0,20. Analisis jalur ini menggunakan bantuan program IBM SPSS Statistics 20, yang merupakan program SPSS versi ke 20 buatan IBM. Besarnya pengaruh peubah lain di luar model ditentukan dengan menghitung koefisien analisis jalur yang menunjukkan error dengan menggunakan persamaan (Widarjono, 2010; Suliyanto, 2011):

di mana:

$$
\mathrm{Pe}=\sqrt{ } 1-\mathrm{R} 2
$$

Pe : koefisien analisis jalur

R2 : koefisien determinasi.

Penentuan besarnya pengaruh, baik pengaruh langsung, pengaruh tidak langsung dan pengaruh total peubah eksogenous terhadap peubah endogenous dihitungberdasarkan petunjuk, Everitt dan Dunn (2001), Supranto (2004), dan Sarwono (2007)dengan metode analisis data multivariat dependensi yang digunakan untuk menguji hipotesis hubungan asimetris yang dibangun atas dasar kajian teori tertentu, dengan tujuan untuk mengetahui pengaruh langsung dan tidak langsung seperangkat variabel penyebab terhadap variabel akibat. Diagram hasil analisis jalur dibuat dengan bantuan program AMOS 16.0.

\section{HASIL DAN PEMBAHASAN}

\section{Karakteristik Lingkungan dan Produksi Tambak}

Nilai rata-rata produktivitas tambak di Kabupaten Indramayu adalah $751,471 \mathrm{~kg} / \mathrm{ha} /$ siklus (Tabel 1). Jumlah produksi yang dihasilkan merupakan produksi dari ikan bandeng. Hasil yang didapatkan merupakan produktivitas pada satu siklus yaitu pada musim kemarau yaitu pada bulan Mei sampai dengan bulan Oktober. Pada siklus berikutnya yaitu pada musim penghujan yaitu pada bulan November sampai dengan bulan April, rata-rata pembudidaya tambak di Kabupaten Indramayu menerapkan sistem budidaya monokultur semi intensif dan intensif dengan harapan memperoleh produksi yang lebih besar dan menggunakan sistem budidaya tambak dengan pola polikultur dengan pertimbangan efisiensi pemanfaatan lahan yang digunakan. Pemilihan lokasi untuk usaha budidaya tambak merpakan salah satu faktor yang menentukan keberhasilan budidaya. Faktor yang perlu dipertimbangkan adalah faktor pemanfaatan sumberdaya alam secara maksimal, untuk mendapatkan biaya produksi yang minimal. Beberapa faktor yang penting untuk diperhatikan adalah posisi lahan tambak untuk memenuhi kebutuhan air dalam budidaya, sumber air agar tambak mudah mendapatkan air langsung maupun melalui saluran air dalam hal ini berhubungan dengan kualitas air untuk pemeliharaan harus terjaga, kemudian kondisi tanah yang baik yang mampu mempertahankan air selama di butuhkan.

Tabel 1. Statistik deskriptif produksi bandengdi tambak Kabupaten Indramayu, Provinsi Jawa Barat (Descriptivestatisticson theproduction ofmilkfishpondsIndramayu district, provinceWest Java)

\begin{tabular}{lrrrr}
\hline \multicolumn{1}{c}{ Faktor/Peubah } & Minimum & Maksimum & Rata-Rata & Standar Deviasi \\
\hline Produksi : & & & & \\
Padat Penebaran (ekor/ha) & 2000,0 & 30000,0 & 8198,2 & 7022,71 \\
Berat Ikan Panen Rata-Rata & 100,00 & 1000,00 & 297,26 & 197,888 \\
(gram/ekor) & & & & \\
Produktivitas (kg/ha/siklus)Lama & 44,444 & 1500,000 & 751,471 & 417,4129 \\
Pemeliharaan (hari) & 90,0 & 420,0 & 211,6 & 89,71 \\
\end{tabular}


Rendahnya produktivitas tambak disebabkan olehrendahnya keberhasilan hidup (survival rate) danpertumbuhan (growth rate) serta ketidakstabilan produksi,yang diduga disebabkan karena penurunan kualitaslingkungan,dalam hal ini dikarenakan kondisi air dan tanah yang dapat menimbulkan adanya penyakit, kesalahan manajemen lingkungan perairan dan penerapan teknologi budidaya.

Tingkat produktivitas bandeng dalam Tambak ditentukan oleh faktor laju pertumbuhan, sintasan, kuantitas, dan kualitas pakan serta pengelolaan budi daya.Padat penebaran dan lama pemeliharaan berpengaruh terhadap produktivitas yang dihasilkan, padat penebaran pada petak pembesaran yang dianjurkan sebanyak 5000-7000 ekor/ha.Padat penebaran dapat berfluktuatif tergantung dari kondisi pertambakan yang tersedia, baik tingkat kesuburan tambaknya maupun kondisi perairannya (Sudradjat et al., 2011) Berat bandeng yang dapat dipanen setelah mencapai ukuran konsumsi (300-500 g/ekor) dengan lama pemeliharaan 3-6 bulan dari gelondongan. Sementara itu, bandeng super dapat dipanen setelah berukuran 800 g/ekor dengan masa pemeliharaannya selama 120 dari gelondongan ukuran 100-150 g/ekor (Anonim, 2010).Dari hal tersebut dapat menjelaskan bahwa produktivitas bandeng di kabupaten indramayu termasuk rendah, hal ini dapat dilihat dari rata-rata padat tebar yaitu 8198 ekor/ha dan berat rata-rata hasil panen yaitu 297 gram/ekor dengan lama pemeliharaan rata-rata 211 hari.

Rata-rata potensial redoks (Eh) tanah tambak di Kabupaten Indramayu bernilai negatif yaitu $-140,7$ $\mathrm{mV}$ yang menunjukkan bahwa tanah dalam kondisi tereduksi,hal ini ditunjukkan juga oleh nilai $\mathrm{pH}_{\mathrm{f}}$, nilai $\mathrm{pH}$ yang diukur langsung di lapangan bernilai rata-rata bernilai 6,975. Penggenangan akan meningkatkan $\mathrm{pH}$ pada tanah masam dan menurunkan $\mathrm{pH}$ pada tanah alkalin. Pada awal penggenangan $\mathrm{pH}$ akan menurun drastis selama beberapa hari pertama, kemudian mencapai titik minimum dan dalam beberapa hari kemudian $\mathrm{pH}$ meningkat secara asimtot hingga mencapai nilai $\mathrm{pH}$ yang stabil yaitu 6,7-7,2. Pada $\mathrm{pH}$ ini terjadi perubahan keseimbangan ion-ion hidroksida, karbonat, sulfida dan silikat (Ponnamperuma, 1972).Hal ini disebabkan karena pengambilan contoh tanah dilakukan pada tambak yang sementara dalam proses budidaya, sehingga tambak dalam keadaan tergenang air, mengakibatkan tambak dalam kondisi tereduksi seperti yang dijelaskan sebelumnya.

Sedangkan $\mathrm{pH}_{\mathrm{Fox}}$ adalah $\mathrm{pH}$ tanah yang diukur di lapangan setelah dioksidasi sempurna dengan $\mathrm{H}_{2} \mathrm{O}_{2}$ (hidrogen peroksida) 30\% (Ahern et al.,1998). Nilai dari $\mathrm{pH}_{\mathrm{Fox}}$ merupakan indikator untuk mengetahui kecepatan oksidasi yang terjadi pada tanah, hal ini erat kaitannya dengan proses oksidasi dalam tanah, karena Pirit yang semula stabil dan tidak berbahaya pada kondisi anaerob atau tergenang, akan teroksidasi bila kondisi berubah menjadi aerob. Hal ini berkaitan dengan kemasaman tanah dan kecepatan oksidasi pirit oleh $\mathrm{Fe}^{3+}$ yang sangat dipengaruhi oleh $\mathrm{pH}$, karena $\mathrm{Fe}^{3+}$ hanya larut pada nilai $\mathrm{pH}$ di bawah 4 dan Thiobacillus ferrooxidans yang dapat mengoksidasi ion besi tidak tumbuh pada $\mathrm{pH}$ yang tinggi. Besi oksida dan pirit di dalam tanah mungkin secara fisik berada pada tempat yang berdekatan, namun ada tidaknya reaksi diantara mereka sangat dipengaruhi oleh kelarutan $\mathrm{Fe}^{3+}$.Kecepatan oksidasi pirit cenderung bertambah dengan menurunnya $\mathrm{pH}$ tanah. Dari hal tersebut dapat diketahui bahwa daerah-daerah yang memiliki konsentarsi $\mathrm{pH}_{\mathrm{FOX}}$ rendah akan dapat mengakibatkan terjadinya proses oksidasi dengan kecepatan oksidasi berdasarkan nilai $\mathrm{pH}$ di bawah 4 dan yang memiliki nilai $\mathrm{pH}_{\mathrm{FOx}}$ tinggi, disebabkan oleh lahan tambak merupakan lahan hutan mangrove yang baru dibuka, sehingga memiliki keadaan tanah yang asam. $\mathrm{pH}_{\mathrm{F}}$ dan $\mathrm{pH}_{\mathrm{FOx}}$ tanah tambak di Kabupaten Indramayu pada Tabel 2 menunjukkan nilai $\mathrm{pH}_{\mathrm{F}}-\mathrm{pH}_{\mathrm{FOX}}$ yang rendah sehingga tanah tambak di Kabupaten Indramayu tidak memiliki potensi kemasaman yang tinggi.

Kandungan bahan organik tanah di tambak Kabupaten Indramayu bervariasi pada Tabel 2, tergolong rata-rata yang menunjukkan bahwa tanah tambak di Kabupaten Indramayu tidak tergolong sebagai tanah organosol atau tanah gambut. Tanah gambut adalah tanah yang dicirikan dengan kandungan bahan organik yang melebihi 20\% (Boyd et al., 2002).Konsentrasi $\mathrm{PO}_{4}$ di tanah tambak Kabupaten Indramayu tergolong baik dengan nilai rata-rata 52,34 ppm. Ketersediaan fosfat $\left(\mathrm{PO}_{4}\right)>60 \mathrm{ppm}$ dalam tanah tambak dapat digolongkan sebagai slight atau tergolong baik 
dengan faktor pembatas yang sangat mudah diatasi (Karthiket al., 2005).

Tabel 2. Statistik deskriptif kualitas tanah di tambak mono bandeng Kabupaten Indramayu, Provinsi Jawa Barat

(Descriptive statisticsof soil qualityinmonomilkfishpondsIndramayuregency, West Java Province)

\begin{tabular}{lrrrr}
\hline \multicolumn{1}{c}{ Faktor/Peubah } & Minimum & Maksimum & Rata-Rata & Standar Deviasi \\
\hline Kualitas Tanah : & & & & \\
$\mathrm{pH}_{\mathrm{F}}$ & 5,770 & 7,430 & 6,975 & 0,4877 \\
$\mathrm{pH}_{\mathrm{FOX}}$ & 2,550 & 8,080 & 5,668 & 1,4863 \\
$\mathrm{pH}_{\mathrm{F}}-\mathrm{pH}_{\mathrm{FOX}}$ & $-1,290$ & 4,770 & 1,307 & 1,5210 \\
Potensial redoks (mV) & $-366,0$ & 166,0 & $-140,7$ & 121,52 \\
$\mathrm{C}$. Organik (\%) & 0,152 & 18,355 & 2,415 & 4,0603 \\
$\mathrm{~B}$. Organik (\%) & 0,262 & 31,644 & 4,163 & 7,0000 \\
$\mathrm{~N}$. Total (\%) & 0,042 & 1,291 & 0,168 & 0,2847 \\
$\mathrm{PO}_{4}(\mathrm{ppm})$ & 15,33 & 146,59 & 52,34 & 35,585 \\
$\mathrm{P}_{2} \mathrm{O}_{5}(\mathrm{pmm})$ & 11,45 & 109,56 & 39,12 & 26,595 \\
$\mathrm{SKCl}(\%)$ & 0,008 & 0,120 & 0,034 & 0,0272 \\
$\mathrm{Fe}(\mathrm{ppm})$ & 199,00 & 1892,75 & 1084,85 & 725,364 \\
$\mathrm{Al}(\mathrm{ppm})$ & 29,00 & 134,25 & 86,62 & 31,610 \\
$\mathrm{Pasir}(\%)$ & 40,0 & 72,0 & 53,8 & 9,21 \\
$\mathrm{Liat}(\%)$ & 0,0 & 48,0 & 18,0 & 15,29 \\
Debu (\%) & 8,0 & 44,0 & 28,2 & 11,09 \\
\hline
\end{tabular}

Tabel 3. Statistik deskriptif kualitas air di tambak mono bandeng Kabupaten Indramayu, Provinsi Jawa Barat (Descriptive statisticsof waterqualityinmonomilkfishpondsIndramayuregency, West Java Province)

\begin{tabular}{lrrrr}
\hline \multicolumn{1}{c}{ Faktor/Peubah } & Minimum & Maksimum & Rata-Rata & Standar Deviasi \\
\hline Kualitas Air : & & & & \\
$\mathrm{Suhu}\left(0^{\mathrm{C}}\right)$ & 29,340 & 34,850 & 32,369 & 1,6473 \\
$\mathrm{TDS}$ & 13,630 & 97,230 & 49,956 & 29,8131 \\
$\mathrm{Salinitas}(\mathrm{ppt})$ & 12,380 & 118,670 & 55,779 & 37,3516 \\
$\mathrm{DO}(\mathrm{mg} / \mathrm{L})$ & 3,754 & 6,783 & 5,526 & 1,0285 \\
$\mathrm{pH}$ & 7,920 & 8,710 & 8,322 & 0,2228 \\
$\mathrm{pHmV}$ & $-98,00$ & $-52,50$ & $-75,79$ & 12,620 \\
$\mathrm{ORP}$ & $-137,50$ & 18,70 & $-13,69$ & 41,484 \\
$\mathrm{NO}_{3}-\mathrm{N}(\mathrm{mg} / \mathrm{L})$ & 0,02910 & 2,56250 & 0,64610 & 0,709679 \\
$\mathrm{NO}_{2}-\mathrm{N}(\mathrm{mg} / \mathrm{L})$ & 0,00010 & 0,09260 & 0,03324 & 0,027064 \\
$\mathrm{NH}_{3}-\mathrm{N}(\mathrm{mg} / \mathrm{L})$ & 0,00320 & 0,48750 & 0,15039 & 0,107313 \\
$\mathrm{PO}_{4}-\mathrm{P}(\mathrm{mg} / \mathrm{L})$ & 0,03720 & 8,07380 & 0,68535 & 1,876650 \\
$\mathrm{Fe}^{(\mathrm{mg} / \mathrm{L})}$ & 0,00010 & 0,04950 & 0,01134 & 0,015564 \\
$\mathrm{SiO}_{2}(\mathrm{mg} / \mathrm{L})$ & 0,00130 & 0,03410 & 0,01742 & 0,007458 \\
$\mathrm{SO}_{4}(\mathrm{mg} / \mathrm{L})$ & 1635,70 & 2812,75 & 2306,65 & 338,163 \\
$\mathrm{TSS}^{(\mathrm{mg} / \mathrm{L})}$ & 44,0 & 368,0 & 128,3 & 79,37 \\
$\mathrm{BOT}_{(\mathrm{mg} / \mathrm{L})}$ & 17,570 & 30,582 & 26,355 & 3,3389 \\
\hline
\end{tabular}

Rata-rata kandungan pasir umumnya tinggi dengan rata-rata $53,8 \%$ dan kandungan liat tergolong rendah dengan nilai rata-rata $18,0 \%$ karenatanah tambak sering dijumpai bertekstur halus dengan kandungan liat minimal 20-30\% untuk menahan peresapan ke samping(Boyd, 1995). Secara kimia, tekstur tanah demikian juga tidak mampu menyimpan unsur hara dan memiliki daya sanggah tanah yang rendah sehingga fluktuasi $\mathrm{pH}$ dapat lebih besar.

Suhu air di pertambakan Kabupaten Indramayu pada Tabel 3 menunjukkan bahwa suhu air di pertambakan masih dapat digolongkan layak untuk

Faktor Lingkungan yang Mempengaruhi Produktivitas Menggunakan Aplikasi Analisis Jalur di Tambak Bandeng Kabupaten Indramayu, Provinsi Jawa Barat 
tambak bandeng karena suhu air yang baik untuk ikan bandeng adalah $27-31^{\circ} \mathrm{C}$ (Ismail et al., 1993). Sedangkan untuk nilai salinitas, ikan bandeng dapat tumbuh optimal pada salinitas air 15-30 ppt (Ismail et al., 1993). Nilai salinitas yang didapatkan berdasarkan hasil penelitian berkisar antara 12,38 sampai 118,67 ppt dengan rata-rata 55,779 ppt. Nilai salinitas 118,67 didapatkan pada tambak yang telah produksi ikan dan akan digunakan untuk tambak garam, dimana pada tambak disekitarnya sudah digunakan untuk tambak garam, nilai tersebut menunjukkan adanya pengaruh dari tambak garam sekitarnya. Di kabupaten Indramayu beberapa tambak garam dimanfaatkan oleh para pembudidaya untuk digunakan sebagai usaha tambak garam sambil menunggu tambak digunakan lagi untuk budidaya ikan atau udang, utamanya pada musim kemarau.Hal tersebut juga dapat dilihat dari ratarata nilai salinitas yang tinggi karena pengukuran dilaksanakan pada saat musim kemarau yang menyebabkan terjadinya penguapan pada air tambak.

Batas toleransi organisme akuatik terhadap $\mathrm{pH}$ bervariasi dan dipengaruhi oleh banyak faktor, antara lain: suhu oksigen terlarut, alkalinitas dan adanya anion dan kation serta jenis dan stadium organisme. Pada umumnya $\mathrm{pH}$ air yang baik bagi organisme akuatik adalah 6,5-9,0; pada $\mathrm{pH} 9,5-$ 11,0 dan 4,0-6,0 mengakibatkan produksi rendah dan jika lebih rendah dari 4,0 atau lebih tinggi 11,0 akan meracuni ikan (Poernomo, 1988). Dari Tabel 3 menunjukkan bahwa ada tambak di Kabupaten Indramayu yang $\mathrm{pH}$ air tergolong netral sampai basa. Telah dilaporkan sebelumnya, bahwa tambak di Kabupaten Indramayu tergolong tanah aluvial nonsulfat masam, sehingga $\mathrm{pH}$ airnya tergolong netral sampai basa (Tabel 2).

Oksigen terlarut sangat esensial bagi pernapasan dan merupakan salah satu komponen utama dalam metabolisme akuatik. Kebutuhan organisme akan oksigen terlarut sangat bervariasi bergantung kepada jenis, stadium, dan aktivitasnya. Oksigen terlarut air tambak di Kabupaten Indramayu tergolong sesuai untuk budidaya tambak. Oleh karena budidaya yang diaplikasikan oleh pembudidaya tambak di Kabupaten Indramayu tergolong teknologi tradisional, sehingga masalah kandungan oksigen terlarut belum menjadi masalah. Batas oksigen terlarut untuk ikan bandeng tumbuh dengan baik pada kisaran oksigen terlarut 3-8 mg/L (Ismail et al, 1993).

Nitrat $\left(\mathrm{NO}_{3}\right)$ adalah bentuk utama nitrogen di perairan alami dan merupakan nutrien utama bagi pertumbuhan tanaman dan alga. Nitrat tidak bersifat toksik terhadap organisme akuatik. Dari Tabel 1 terlihat bahwa kandungan nitrat air tambak di Kabupaten Indramayu juga tergolong tinggi. Konsentrasi $\mathrm{NO}_{3}$ pada perairan alami hampir tidak pernah lebih dari $0,1 \mathrm{mg} / \mathrm{L}$. Konsentrasi $\mathrm{NO}_{3}$ lebih dari $5 \mathrm{mg} / \mathrm{L}$ menggambarkan terjadinya pencemaran antropogenik yang berasal dari aktivitas manusia dan tinja hewan. Konsentrasi $\mathrm{NO}_{3}$ yang lebih dari $0,2 \mathrm{mg} / \mathrm{L}$ dapat mengakibatkan terjadinya eutrofikasi perairan yang selanjutnya menstimulir pertumbuhan alga dan tumbuhan air secara pesat.

Nitrit $\left(\mathrm{NO}_{2}\right)$ merupakan bentuk peralihan antara amonia dan nitrat (nitrifikasi) dan antara nitrat dan gas nitrogen (denitrifikasi). Seperti halnya $\mathrm{NH}_{3}$, maka $\mathrm{NO}_{2}$ juga beracun terhadap ikan, karena mengoksidasikan besi $(\mathrm{Fe})$ di dalam hemoglobin. Dalam bentuk ini kemampuan darah untuk mengikat oksigen terlarut sangat merosot (Poernomo, 1988). Pada udang yang darahnya mengandung tembaga $(\mathrm{Cu})$ (hemocyanin) mungkin terjadi oksidasi $\mathrm{Cu}$ oleh $\mathrm{NO}_{2}$ dan memberikan akibat yang sama seperti pada ikan (Poernomo, 1988). Kandungan nitrit air tambak Kabupaten Indramayu tergolong tidak tinggi. Konsentrasi $\mathrm{NO}_{2}$ pada perairan relatif kecil karena segera dioksidasi menjadi nitrat. Perairan alami mengandung $\mathrm{NO}_{2}$ sekitar $0,001 \mathrm{mg} / \mathrm{L}$ dan sebaliknya tidak melebihi $0,06 \mathrm{mg} / \mathrm{L}$ (Sawyer, 1978). Di perairan, konsentrasi $\mathrm{NO}_{2}$ jarang melebihi $1 \mathrm{mg} / \mathrm{L}$ (Sawyer, 1978). Konsentrasi $\mathrm{NO}_{2}$ yang lebih dari $0,05 \mathrm{mg} / \mathrm{L}$ dapat bersifat toksik bagi organisme akuatik sang sangat sensitif (Moore, 1991).

Amonia dapat berada dalam bentuk molekul $\left(\mathrm{NH}_{3}\right)$ atau bentuk ion $\mathrm{NH}_{4}$, dimana $\mathrm{NH}_{3}$ lebih beracun daripada $\mathrm{NH}_{4}$ (Poernomo, 1988). $\quad \mathrm{NH}_{3}$ dapat menembus bagian membran sel lebih cepat daripada $\mathrm{NH}_{4}$ (Coltet al., 1981). Konsentrasi amonia air tambak Kabupaten Indramayu tergolong cukup tinggi di perairan. Konsentrasi $\mathrm{NH}_{3} \quad 0,05-0,20 \quad \mathrm{mg} / \mathrm{L}$ sudah menghambat pertumbuhan organisme akuatik pada umumnya. Apabila konsentrasi $\mathrm{NH}_{3}$ lebih dari $0,2 \mathrm{mg} / \mathrm{L}$, perairan bersifat toksik bagi beberapa jenis ikan 
(Sawyer, 1978). Ikan tidak dapat bertoleransi terhadap konsentrasi $\mathrm{NH}_{3}$ yang terlalu tinggi, karena dapat mengganggu proses pengikatan oksigen oleh darah dan pada akhirnya dapat mengakibatkan sufokasi.

Silika ( $\mathrm{Si}$ ) telah sebagai unsur konservatif dari mineral di mana air tawar di sungai di seluruh dunia mengandung rata-rata $\mathrm{Si}$ setara $6,1 \mathrm{mg} / \mathrm{L}$ (Boyd, 1994). Konsentrasi $\mathrm{SiO}_{2}$ air tambak berkisar dari 0,0013 sampai $0,0341 \mathrm{mg} / \mathrm{L}$ dengan rata-rata $0,01742 \mathrm{mg} / \mathrm{L}$. Silika dibutuhkan untuk pertumbuhan diatom. Telah dibuktikan bahwa dalam beberapa konsentrasi silika perairan dapat mengatur kelimpahan diatom .

Air tambak tidak berbeda dengan air kolam lainnya, yang membedakannya adalah air tambak terasa asin karena mengandung garam sedangkan air kolam berasa tawar.Sejak terjadinya laut di permukaan bumi ini, laut menjadi tempat penampungan garam-garam dan batuan yang diangkut dari darat, letusan gunung berapi dan meteorolet yang datang dari angkasa luar.Akibatnya laut menjadi penuh dengan berbagai jenis senyawa yang kita kenal kemudian masuk ke tambak-tambak yang ada di pinggiran pantai.Berbicara tentang air tambak pasti berbicara tentang air laut.Sehingga pembahasan air tambak pun tidak terlepas dari air laut. Unsur-unsur kimia yang terdapat di dalam air laut atau tambak yaitu berupa garam-garam, gas-gas, suspensi dan senyawa organik. Garam-garam tersebut berasal dari hasil erosi batu-batuan yang diangkut oleh sungai dan telah berlangsung dalam kurun waktu yang sangat lama. Beberapa senyawa lain terutama yang berupa gas berasal dari makhluk hidup yang ada didalamnya termasuk unsur oksigen dan nitrogen. Karena senyawa kimia yang ada di dalam laut / tambak sangat kompleks, agak sulit untuk menentukan jumlah zat-zat yang terlarut didalamnya, karena diperlukan perangkat peralatan yang lengkap. Perbandingan elemen-elemen tersebut dapat dikatakan tetap. Dengan kata lain konsentrasi zat-zat terlarut dalam air dapat ditentukan apabila salah satu elemennya dapat diketahui. Konsentrasi sulfat pada tambak yaitu $2,712 \mathrm{~g} / \mathrm{kg}$ atau $2712 \mathrm{mg} / \mathrm{L}$ pada salinitas $35 \mathrm{ppt}$ (Anonim, 2007), konsentrasi sulfat hasil pengukuran pada tambak di kabupaten Indramayu yaitu rata-rata $2306,65 \mathrm{mg} / \mathrm{L}$, dengan salinitas ratarata $55,8 \mathrm{ppt}$ dimana rata-rata salinitas tersebut terdapat hasil pengukuran salinitas yang tinggi pada tambak yang habis panen dan dipersiapkan untuk tambak garam. Sehingga kandungan sulfat masih dibawah nilai komposisi kimia dalam hal konsentrasi sulfat pada tambak.

Bahan organik total air menggambarkan kandungan bahan organik total suatu perairan yang terdiri dari bahan organik terlarut, tersuspensi dan koloid. Bahan organik di perairan terdapat sebagai plankton, partikel-partikel tersuspensi dari bahan organik yang mengalami perombakan (detritus) dan bahan-bahan organik total yang berasal dari daratan dan terbawa oleh aliran sungai. Kandungan bahan organik total air di tambak Kabupaten Indramayu berkisar 17,57 - 30,58 mg/L dengan rata-rata 26,355 $\mathrm{mg} / \mathrm{L}$ (Tabel 3). Kandungan bahan organik total dalam air laut biasanya rendah dan tidak melebihi $3 \mathrm{mg} / \mathrm{L}$. Perairan dengan kandungan bahan organik total di atas $26 \mathrm{mg} / \mathrm{L}$ adalah tergolong perairan yang subur (Reid, 1961).

Di perairan, unsur fosfor tidak ditemukan dalam bentuk bebas sebagai elemen, melainkan dalam bentuk senyawa anorganik yang terlarut (ortofosfat dan polifosfat) dan senyawa organik yang berupa partikulat. Fosfat merupakan bentuk fosfor yang dapat dimanfaatkan oleh tumbuhan (Dugan, 1972). Konsentrasi fosfat pada perairan alami berkisar antara 0,005-0,020 mg/L, sedangkan pada air tanah bisanya berkisar $0,02 \quad \mathrm{mg} / \mathrm{L}$ (UNESCO/WHO/UNEP, 1992). Konsentrasi $\mathrm{PO}_{4}$ jarang melebihi $0,1 \mathrm{mg} / \mathrm{L}$, meskipun pada perairan eutotrof. Konsentrasi $\mathrm{PO}_{4}$ pada perairan alami jarang melebihi $1 \mathrm{mg} / \mathrm{L}$ (Boyd, 1988). Berdasarkan konsentrasi fosfat, perairan diklasifikasikan menjadi tiga yaitu: perairan dengan kesuburan rendah, yang memiliki konsentrasi fosfat berkisar antara $0-0,02 \mathrm{mg} / \mathrm{L}$; perairan dengan tingkat kesuburan sedang, yang memiliki konsentrasi fosfat $0,021-0,05 \mathrm{mg} / \mathrm{L}$; dan perairan dengan tingkat kesuburan tinggi, yang memiliki konsentrasi fosfat 0,051-0,10 mg/L (Liaw, 1969). Berdasarkan kriteria tersebut menunjukkan bahwa kualitas air tambak di Kabupaten Indramayu tergolong tingkat kesuburan rendah, sedang, dan tinggi.

Padatan tersuspensi total (total suspended solid) menggambarkan bahan baik organik maupun nonorganik yang terkandung dalam larutan dalam 
bentuk tersuspensi. Padatan tersuspensi total yaitu bahan-bahan tersuspensi berukuran diameter $>1$ $\mu \mathrm{m}$, tertahan pada saringan millipore berdiameter pori $0,45 \mu \mathrm{m}$ (Effendi, 2003). Padatan tersuspensi total berupa lumpur, pasir halus dan jasad renik yang melayang-layang di perairan. Berdasarkan hal tersebut, padatan tersuspensi total air tambak di Kabupaten Indramayu tergolong baik.
Hubungan Lingkungan dan Produksi Tambak Telah dijelaskan sebelumnya bahwa peubah kualitas tanah merupakan peubah bebas dan peubah eksogenous dalam penelitian ini. Dari 15 peubah kualitas tanah (Tabel 1) yang dianalisis ternyata hanya 2 peubah yang mempengaruhi produksi bandeng di tambak Kabupaten Indramayu yaitu: potensial redoks tanah (EhT) dan pHF tanah (pHFT) (Gambar 2).

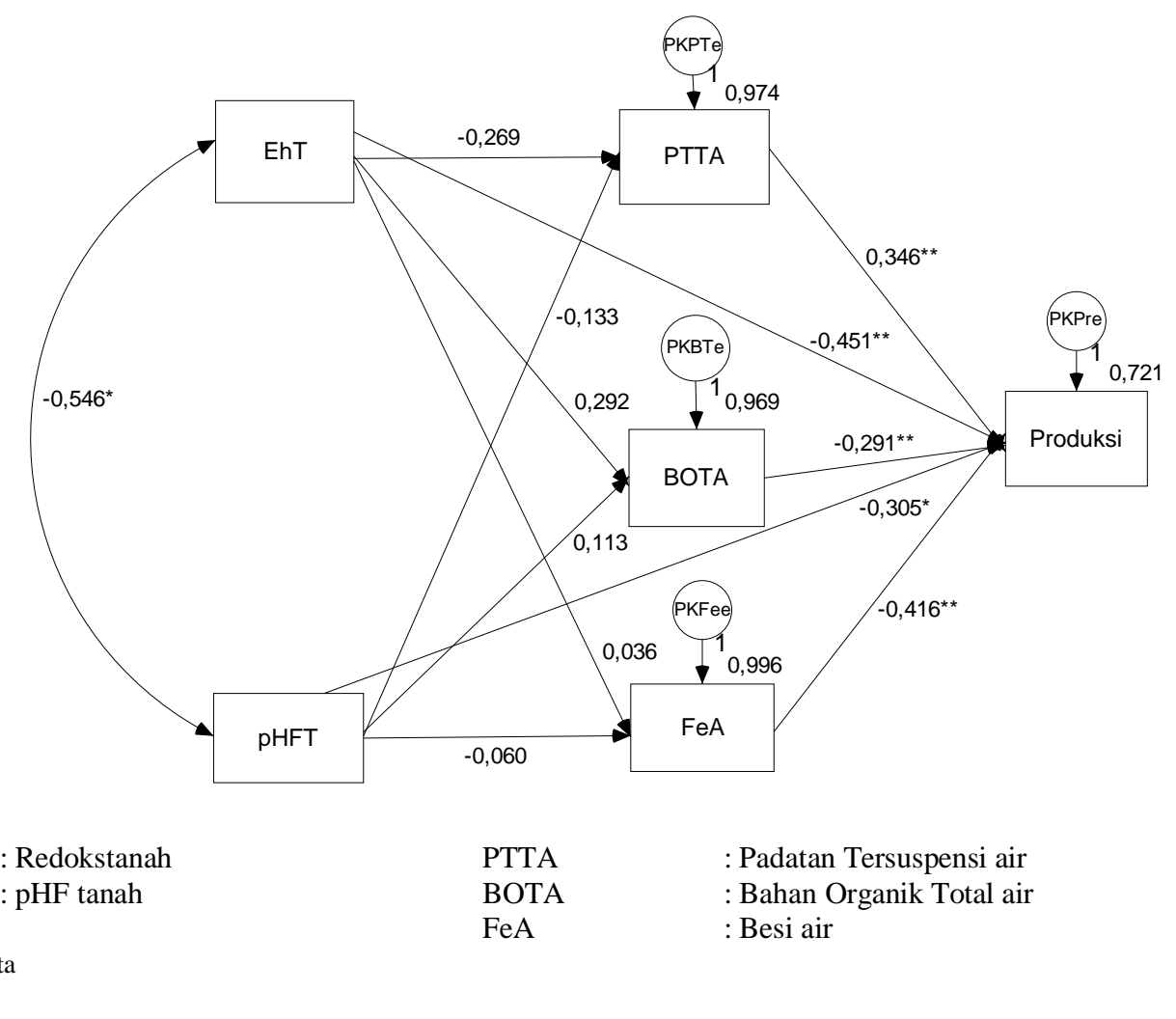

$* *=<0,2$ sangat nyata

$*=<0,3$ nyata

Gambar 2. Diagram hasil analisis jalur kualitas tanah terhadap kualitas air dan produksi total di tambak Kabupaten Indramayu,Provinsi Jawa Barat(Pathdiagram (analysisof soil qualityon water qualityandproductionTotal inpondsIndramayuregency, West Java Province)

EhT dan pHFT berpengaruh sangat nyata dengan pengaruh langsung (direct effect) sebesar $-0,451$ dan $-0,305 \quad(P<0,2)$ terhadap produksi bandeng. Peningkatan potensial redoks tanah menciptakan kondisi tanah dasar tambak yang lebih baik yang dapat berdampak pada penumbuhan makanan alami yang lebih baik sehingga produksi ikan bandeng dapat meningkat. Perubahan sifat-sifat kimia yaitu perubahan potensial redoks (Eh) dan kemasaman tanah $(\mathrm{pH})$ tanah yang merupakan dua faktor utama yang saling berkaitan dalam mempengaruhi kelarutan dan ketersediaan hara dan transformsinya di dalam tanah serta bepengaruh terhadap pertumbuhan dan produksi tambak.

Hal ini berkaitan dengan unsur $\mathrm{N}$ dalam tanah, Nitrogen $(\mathrm{N})$ sebagai salah satu unsur hara makro yang sangat penting dan terdapat dalam tanah dalam bentukorganik, yaitu sekitar 90\% (Stevenson, 1982).Mineralisasi N-organik di dalam tanah sangat menentukan ketersediaan $\mathrm{N}$ dan kesuburan tanah (Nadelhoffer, 1990).Bentuk kimia $\mathrm{N}$ termasuk interaksi sederhana dengan sistem biologi di dalam tanah terkait erat dengan nilai potensial redoks $(E h)$ dan $\mathrm{pH}$ yang berkembang

Faktor Lingkungan yang Mempengaruhi Produktivitas Menggunakan Aplikasi Analisis Jalur di Tambak Bandeng Kabupaten Indramayu, Provinsi Jawa Barat 
pada tanah tersebut. Proses mineralisasi N-organik di dalam tanah merupakan proses redoks yang melibatkan donor dan akseptor electron (Bohn et al., 1985). Penentuan senyawa yang bertindak sebagai akseptor elektron terkait erat dengan perkembangan nilai $E h$ di dalam tanah (Bohn et al., 1985). Pada tanah-tanah yang kondisinya aerob (nilai Eh berkisar antara 0,3 hingga 0,8 V), oksigen bertindak sebagai akseptor elektron, sedangkan pada tanah - tanah yang kondisinya anaerob (nilai Eh umumnya berkisar antara 0,2 hingga $-0,4 \mathrm{~V}$ ). Hal tersebut dapat menjelaskan bahwa kondisi tanah pada tambak di kabupaten Indramayu berada dalam kondisi anaerob, kondisi ini sangat mempengaruhi ketersediaan unsure hara pada tanah, yang akan berpengaruh terhadap produksi bandeng. Selain itu, tanah sulfat masam dapat menyebabkan rendahnya produktivitas tambak. sebagai akibat asam sulfurik yang terbentuk karena teroksidasinya pirit akan mempengaruhi mineralmineral tanah. Pada tanah sulfat masam, tanah dasar atau tanah pematang yang terekspos dengan udara dapat menyebabkan terlarutnya pirit yang melarutkan asam sulfat, besi, dan alauminium yang dapat menyebabkan penurunan $\mathrm{pH}$ air. Tanahtanah pada sistem persawahan dan penggenangan akan mendorong perubahan elektrokimia yang mempengaruhi penyediaan dan pengambilan hara (Ponnamperuma, 1984).

Dari 16 peubah kualitas air yang merupakan peubah perantara, tergantung dan endogenous dalam penelitian ini, ternyata hanya 3 peubah yang mempengaruhi produksi bandeng di Kabupaten Indramayu yaitu: padatan tersuspensi total air (PTTA), Bahan Organik Total air (BOTA) dan kandungan besi air (FeA) seperti terlihat pada Gambar 1. Sedangkan nilai pengaruh langsung, tidak langsung, dan total antarpeubah secara lengkap tersaji pada Tabel 4.

Tabel 4. Nilai pengaruh langsung, tidak langsung, dan total setiap korelasi dalam analisis jalur untuk faktor lingkungan dan produksi bandeng di tambak KabupatenIndramayu, Provinsi Jawa Barat (Influencethe value ofdirect, indirect, andtotalevery correlationin the analysispathwaysforenvironmental factorsandproduction of milkfishin pondsIndramayu district, West Java Province)

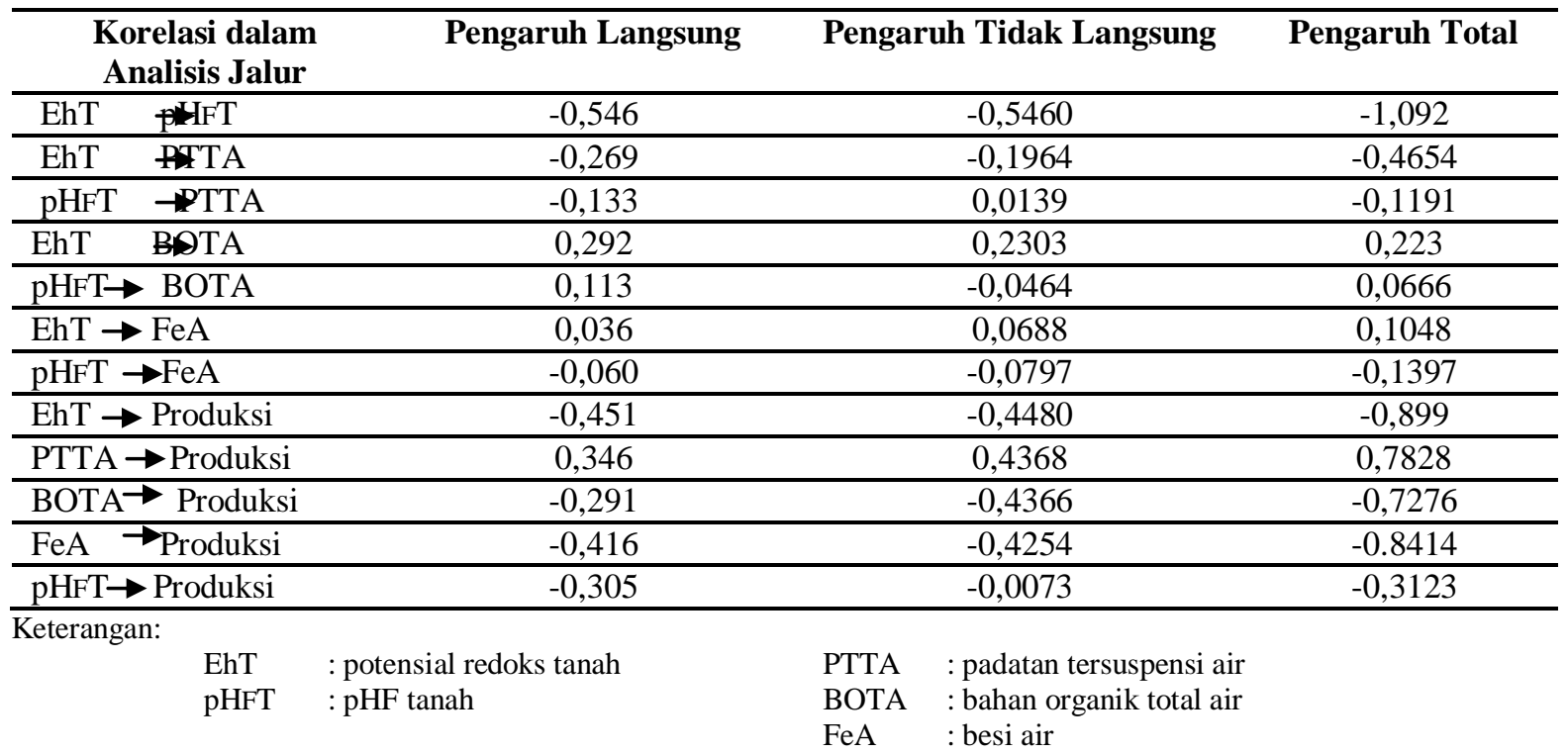

Padatan tersuspensi total air (PTTA) hanya berpengaruh nyata $(P<0,3)$ terhadap produksi bandeng, sedangkan BOTA dan FeA berpengaruh sangat nyata $(P<0,2)$ terhadap produksi dengan pengaruh langsung masing-masing $0,346,-0,291$ dan -0,416 terhadap produksi bandeng. PTTA memberikan pengaruh nyata $(\mathrm{P}<0,2)$ terhadap produksi ikan bandeng di tambak Kabupaten Indramayu dengan pengaruh langsung 0,346. Hal ini menunjukkan bahwa makin tinggi PTTA maka produksi ikan bandeng akan mengalami penurunan. Padatan tersuspensi total berupa lumpur, pasir halus dan jasad renik yang melayang-layang di perairan tidak bersifat toksik dan jika berlebihan 
dapat meningkatkan nilai kekeruhan yang berpengaruh terhadap proses fotosintesis.Hal inilah yang menyebabkan peningkatan kandungan PTTA di tambak yang menyebabkan penurunan produksi ikan bandeng di tambak Kabupaten Indramayu. Padatan tersuspensi mengakibatkan penetrasi sinar matahari ke dalam air berkurang yang akan berpengaruh terhadap regenerasi oksigen serta fotosintesis (Misnani, 2010).Dengan adanya padatan tersuspensi akan memberikan efek yang kurang baik terhadap kualitas badan air karena dapat menyebabkan menurunkan kejernihan air dan dapat mempengaruhi kemampuan ikan untuk melihat dan mengambil makanan. Endapan tersuspensi dapat juga menyumbat insang ikan dan mencegah telur berkembang.

\section{KESIMPULAN DAN SARAN}

Hasil analisis jalur variabel kualitas tanah menunjukkan ada 2 variabel yang mempengaruhi produksi bandeng yaitu potensial redoks tanah dan pHFT, EhT dan pHFT berpengaruh sangat nyata dengan pengaruh langsung (direct effect) sebesar 0,451 dan $-0,305$ terhadap produksi bandeng. Sedangkan variabel kualitas air menunjukkan ada 3 variabel yang mempengaruhi produksi tambak bandeng yaitu padatan tersuspensi total air (PTTA) hanya berpengaruh nyata terhadap produksi bandeng, sedangkan BOTA dan FeA berpengaruh sangat nyata dengan pengaruh langsung masingmasing 0,346, -0,291 dan -0,416 terhadap produksi bandeng di Kabupaten Indramayu.

\section{UCAPAN TERIMA KASIH}

Diucapkan banyak terima kasih kepada Haking Madeng atas bantuannya di lapangan;Rosiana Sabang dan Rahmiyah atas bantuannya dalam analisis kualitas tanah; serta Sutrisyani, Andi Sahrijanna dan Kurnia atas bantuannya dalam analisis air.

\section{DAFTAR PUSTAKA}

Agus, Yusrial, F. dan Sutono. 2006. Penetapan tekstur tanah. Dalam: Kurnia, U., Agus, F., Adimihardja, A. dan Dariah, A. (eds.), Sifat Fisik Tanah dan Metode Analisisnya. Balai
Besar Penelitian dan Pengembangan Sumberdaya Lahan Pertanian, Bogor.hlm. 43-62.

Ahern, C.R. and Rayment, G.E. 1998. Codes for acid sulfate soils analytical methods. In: Ahern, C.R., Blunden, B. and Stone, Y. (eds.), Acid Sulfate Soils Laboratory Methods Guidelines. Acid Sulfate Soil Management Advisory Committee, Wollongbar, NSW. pp. 3.1-3.5.

Ahern, C.R., Blunden, B., Sullivan, L.A., McElnea, A.E., 2004. Soil sampling, handling, preparation and storage for analisys of dried samples. In:Acid Sulfate Soils Laboratory Methods Guidelines. Queensland Department of Natural Resources, Mines and Energy, Indooroopilly, Queensland, Australia, pp. B1-1-B1-5.

Amir, M.F. 2006. Mengolah dan Membuat Interpretasi Hasil Olahan SPSS untuk Penelitian Ilmiah. EDSA Mahkota, Jakarta. $201 \mathrm{hlm}$.

Anonim, 2007.Komposisi Kimia Air Tambak. http://aquablok2b.wordpress.com/2007/10/2 7/komposisi-kimia-air-tambak/] [Diakses 13/01/2014]

Anonim 2010.Budidaya Ikan Bandeng dan Udang. http://space4mm.blogspot.com/2010_04_01 _archive.html. [Diakses 13/01/2014]

Anonim, 2011. Budidaya Air Payau. http:// /www.humasindramayu.com. [Diakses 03/12/2012].

APHA (American Public Health Association). 2005. Standard Methods for Examination of Water and Wastewater. Twentieth edition APHA-AWWA-WEF, Washington, $1185 \mathrm{pp}$.

Bohn, H.L., B.L. McNeal., and G.A. O'Connor.1985.Soil Chemistry (second edition).John Wiley \& Sons Inc. New York, Chichester,Brisbane, Toronto, Singapore. pp. $135-141,248-249$.

Boyd, C.E. 1988. Water Quality of Warmwater Fish Ponds.Fourth printing.Alabama Agricultural Experiment Station, Auburn University, Alabama.

Boyd, C.E. 1994. Chemical characteristic of bottom soil from freshwater and brackishwater aquaculture ponds. Journal of World Aquaculture Society 25: 517-534. 
Boyd, C.E. 1995. Bottom Soils, Sediment, and Pond Aquaculture. Chapman and Hall, New York, 348 pp.

Boyd, C.E., Wood, C.W., Thunjai, T., 2002. Aquaculture Pond Bottom Soil Quality Management. Pond Dynamics/Aquaculture Collaborative Research Support Program Oregon State University, Corvallis, Oregon, $41 \mathrm{pp}$.

Colt, J.E. and Armstrong, D.A. 1981. Nitrogen toxicity to crustaceans, fish, and molluscs. In: L.J. Allen and E.C. Kinney (eds.), Proceedings of the bio-engineering symposium for fish culture. American Fisheries Society, Bethesda, MD. pp. 34-37

Draper, N.R. and H. Smith. 1981. Applied Regression Analysis. $2^{\text {nd }}$ edition. John Wiley \& Sons, New York. 709 pp.

Dugan, P. R. 1972. Biochemical Ecology of Water Pollution. Plenum Press, New York. $159 \mathrm{pp}$.

Effendi, H.2003. Telaah Kualitas Air bagi Pengelolaan Sumber Daya dan Lingkungan Perairan.Penerbit Kanisius, Yogyakarta, $258 \mathrm{hlm}$.

Everitt, B.S. and Dunn, G. 2001. Applied Multivariate Data Analysis. Second edition. Arnold, London. 342 pp.

Hardjowigeno, S., Soekardi, M. Djaenuddin, D, Suharta, N. dan Jordens, E. R. 1996. Kesesuaian Lahan untuk Tambak. Pusat Penelitian Tanah dan Agroklimat, Bogor.17 hlm.

Ismail, A., Poernomo, A., Sunyoto, P., Wedjatmiko, Dharmadi, Budiman, R.A.I. 1993. Pedoman Teknis Usaha Pembesaran Ikan Bandeng di Indonesia. Pusat Penelitian dan Pengembangan Perikanan, Jakarta, $93 \mathrm{hlm}$

Karthik, M., J. Suri, N. Saharan and Biradar, R. S. 2005. Brackish Water Aquaculture Site Selection in Palghar Taluk, Thane district of Maharashtra, India, Using the Techniques of Remote Sensing and Geographical Information System. Aquacultural Engineering 32: 285-302

Liaw, W. K. 1969. Chemical and biological studies of fishponds and reservoirs in Taiwan. Rep. Fish Culture Res., Fish. Series, Chin. Am. Joint Commission on Rural Reconstruction 7, 1-43.
Menon, R.G. 1973. Soil and Water Analysis: A Laboratory Manual for the Analysis of Soil and Water. Proyek Survey O.K.T. Sumatera Selatan, Palembang.

Misnani. 2010. Praktikum Teknik Lingkungan Total Padatan Terlarut.Online http://misnanidulhadi.blogspot.com/.

Diakses pada tanggal 20 Januari 2014.

Moore, J.W. 1991. Inorganic Contaminants of Surface Water. Springer-Verlag, New York. 334 pp.

Muir, J. F. and Kapetsky, J. M. 1988. Site selection decisions and project cost: the case of brackish water pond systems. In: Aquaculture Engineering Technologies for the Future. Hemisphere Publishing Corporation, New York. pp. 45-63.

Mustafa, A. dan Ratnawati, E. 2005. Faktor pengelolaan yang berpengaruh terhadap produksi rumput laut (Gracilaria verrucosa) di tambak tanah sulfat masam (studi kasus di Kabupaten Luwu, Provinsi Sulawesi Selatan). Jurnal Penelitian Perikanan Indonesia 11(7), 67-77.

Mustafa, A. and J. Sammut. 2007. Effect of different remediation techniques and dosages of phosphorus fertilizer on soil quality and klekap production in acid sulfate soil-affected aquaculture ponds. Indonesian AquacultureJournal2(2): 141157.

Nadelhoffer, K. J. 1990. Microlysimeter for measuring nitrogen mineralisation and microbial respiration in aerobic soil incubation.Soil.Sci.Soc.Am.J. 54:411-415.

Poernomo, A. 1988. Pembuatan Tambak Udang di Indonesia. Seri Pengembangan No. 7. Balai Penelitian Perikanan Budidaya Pantai, Maros, 40 hlm.

Ponnamperuma, F. N. 1972. In "Soil Chemistry" (J. Bremner and G. Chesters, eds.), Dekker, Ne, Yark (in press).

Ponnamperuma, F.N. 1984. Effects of flooding on soils.In:Koslowski, T.T. (ed,). Flooding and Plant Growth. Academic Press Inc., New York. pp. 10-45.

Prihandoko., et al.,(2011). Faktor-faktor yang mempengaruhi perilaku nelayan artisanal dalam pemanfaatan sumberdaya perikanan di Pantai Utara Provinsi Jawa Barat.Makara, Sosial Humaniora, Vol. 15, No. 2, Desember 2011: 117-126. 
Reid, G.K. 1961. Ecology of inland water estuaries. Reinhald Published Co. New York. 375 pp.

Rutherford, R.D. and Choe, M.K. 1993. Statistical Model for Causal Analysis. John Wiley \& Sons, Inc., New York.

Salam, M. A., Ross, L. G. and Beveridge, C. M. M. 2003. A comparison of development opportunities for crab and shrimp aquaculture in southwestern Bangladesh, using GIS modeling. Aquaculture 220: 477-494.

Sarwono, J. 2007. Analisis Jalur untuk Riset Bisnis dengan SPSS. Penerbit Andi, Yogyakarta. $321 \mathrm{hlm}$.

Sawyer, C.N. and McCarty, P.L. 1978. Chemistry for Environmental Engineering. Third edition. McGraw-Hill Book Company, New York, 532 pp

Sudradjat, A., Wedjatmiko, Setiadharma, T. 2011. Teknologi Budidaya Ikan Bandeng. Pusat Penelitian dan Pengembangan Perikanan Budidaya, Jakarta.

Sulaeman, Suparto dan Eviati. 2005. Petunjuk Teknis Analisis Kimia Tanah, Tanaman, Air, dan Pupuk. Diedit oleh: Prasetyo,
B.H., Santoso, D. dan Widowati, L.R. Balai Penelitian Tanah, Bogor. $136 \mathrm{hlm}$.

Suliyanto. 2011. Ekonometrika Terapan: Teori \& Aplikasi dengan SPSS. Penerbit Andi, Yogyakarta. $311 \mathrm{hlm}$.

Supranto, J. 2004. Analisis Multivariat: Arti \& Interpretasi. Cetakan pertama. Rineka Cipta, Jakarta. 359 hlm.

Stevenson, F. J. 1982. Nitrogen in Agricultural Soil. Madison Wisconsin. USA. pp. 229230.

Swingle, H.S, 1968. Standardization of Chemical Analysis of Water and Pond Muds.In Proceedings of the World Sympson on Warm Water Pond Fish Culture F.A.O. Fisheries Report No.44, Vol 4: 397-421

UNESCO/WHO/UNEP. 1992. Water Quality Assessments. In: Chapman, D. (ed.). Chapman and Hall Ltd., London.

Treece, G. D. 2000. Site selection. In: Stickney, R. R. (ed.), Encyclopedia of Aquaculture. John Wiley \& Sons, Inc., New York. pp. 869-879.

Widarjono, A. 2010. Analisis Statistika Multivariat Terapan. Edisi pertama. UPP STIM YKPN, Yogyakarta. $358 \mathrm{hlm}$. 